\title{
IMPAI is Essential for Embryonic Development and Lithium-Like Pilocarpine Sensitivity
}

\author{
Kim Cryns ${ }^{1,4}$, Alon Shamir ${ }^{2,4}$, Nathalie Van Acker ${ }^{3}$, Itzhak Levi², Guy Daneels', Ilse Goris', \\ J Adriaan Bouwknecht', Luc Andries', Stefan Kass', Galila Agam², Haim Belmaker', Yuly Bersudsky², \\ Thomas Steckler' and Dieder Moechars*, I \\ 'Research and Early Development Europe, Johnson \& Johnson Pharmaceutical Research and Development, Beerse, Belgium; ${ }^{2}$ Stanley Research \\ Center, Faculty of Health Sciences, Ben Gurion University of the Negev and Mental Health Center, Beer-Sheva, Israel; ${ }^{3}$ Histogenex, Antwerp, \\ Belgium
}

Lithium has been the standard pharmacological treatment for bipolar disorder over the last 50 years; however, the molecular targets through which lithium exerts its therapeutic effects are still not defined. We characterized the phenotype of mice with a dysfunctional IMPA I gene $\left(|M P A|^{-1-}\right.$ ) to study the in vivo physiological functions of IMPAI, in general, and more specifically its potential role as a molecular target in mediating lithium-dependent physiological effects. Homozygote IMPA $/^{-1-}$ mice died in utero between days 9.5 and 10.5 post coitum (p.c.) demonstrating the importance of IMPAI in early embryonic development. Intriguingly, the embryonic lethality

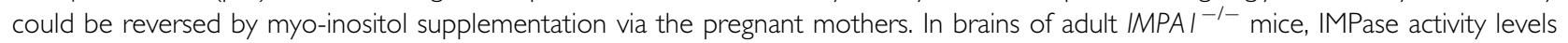
were found to be reduced (up to 65\% in hippocampus); however, inositol levels were not found to be altered. Behavioral analysis of the $|M P A|^{-1-}$ mice indicated an increased motor activity in both the open-field test and the forced-swim test as well as a strongly increased sensitivity to pilocarpine-induced seizures, the latter supporting the idea that IMPA / represents a physiologically relevant target for lithium. In conclusion the $\mid \mathrm{MPA}^{-1-}$ mouse represents a novel model to study inositol homeostasis, and indicates that genetic inactivation of IMPAI can mimic some actions of lithium.

Neuropsychopharmacology (2008) 33, 674-684; doi:I0.1038/sj.npp. I30I43I; published online 25 May 2007

Keywords: IMPA I; lithium; bipolar disorder; pilocarpine; IMPase activity; inositol

\section{INTRODUCTION}

The phosphatidylinositol (PI) cycle is a key intracellular second messenger system in brain as well as in numerous other tissues (Berridge and Irvine, 1989). The dephosphorylation of inositol-1-phosphate to inositol is accomplished by the enzyme inositol monophosphatase (IMPase). This enzyme is widely distributed throughout the body and, as such, might not be considered a likely target for therapeutic intervention. However, attention was focused early on the unique ability of lithium to inhibit this enzyme with a $\mathrm{Ki}$ within the therapeutic range reached during lithium treatment (Hallcher and Sherman, 1980). Lithium salts have been the standard pharmacological treatment for bipolar disorder in the last 50 years (Goodwin and Jamison, 1990). Moreover, the mechanism of the inhibition was determined to be uncompetitive which suggested that the inhibition could become highly rate limiting as substrate concentra-

*Correspondence: Dr D Moechars, Research and Early Development Europe, Johnson \& Johnson Pharmaceutical Research and Development, Turnhoutseweg 30, B-2340 Beerse, Belgium, Tel: + 3214 605915, Fax: + 32 14 606 III, E-mail: dmoechar@prdbe.jnj.com

${ }^{4}$ These authors contributed equally to this work.

Received II September 2006; revised 9 March 2007; accepted 12 March 2007 tions increased during the in vivo treatment (Atack et al, 1995). As a consequence, the 'inositol depletion hypothesis' was proposed to explain lithium's mechanism of action (Berridge et al, 1989). This hypothesis suggests that uncompetitive inhibition of IMPase as well as inositol polyphosphate 1-phosphatase (IPPase) by therapeutically relevant lithium concentrations leads to an accumulation of inositol phosphates and a corresponding depletion of free myo-inositol. Attempts to prove the so called inositol depletion hypothesis' led to numerous studies (for review, see Harwood, 2005). Lithium inhibition of the PI cycle has been relatively easy to demonstrate in in vitro systems with low extracellular inositol concentrations (Berridge et al, 1982). However, reduction of PI turnover in vivo during chronic lithium treatment has not been demonstrated and it has been claimed that high inositol concentrations outside the cells makes lithium inhibition of IMPase less relevant in in vivo situations (Batty and Downes, 1994). One in vivo demonstration of a lithium effect dependent on inositol is lithium pilocarpine-induced seizures. Rodents treated with lithium acutely or chronically are exquisitely sensitive to pilocarpine leading to a unique limbic seizure behavior (Honchar et al, 1983). This behavior is stereospecifically reversed by intracerebroventricular myo-inositol but not by its stereoisomer chiro-inositol, that does not enter the PI 
cycle (Kofman et al, 1993). However, lithium pilocarpineinduced seizures have little face validity as a behavioral model for the mood-stabilizing effects of lithium and may merely represent a bioassay for inositol depletion (Einat et al, 2003).

The interpretation of the inositol depletion hypothesis has been complicated further by the discovery of a second gene coding for IMPase named IMPA2 (Sjoholt et al, 2000; Yoshikawa et al, 2000). IMPA2 is located on chromosome 18 near a region implicated in linkage studies of manic depressive illness (Berrettini et al, 1994; Rojas et al, 2000). IMPA2 produces an mRNA transcript but has been shown to produce IMPase activity (Yoshikawa et al, 1997; Ohnishi et al, 2007). We have recently reported that IMPA2 KO mice have lower kidney inositol levels suggesting that the IMPA2 gene contributes to kidney IMPase activity. Nevertheless, deleting the IMPA2 gene does not mimic the behavioral effects of lithium (Cryns et al, 2007).

To determine the physiological functions of IMPA1 in vivo and study the potential role of IMPA1 in mediating the physiological effects of lithium, we studied a mouse model in which the IMPA1 gene was inactivated by targeted mutagenesis.

\section{MATERIALS AND METHODS}

\section{Generation of $I M P A 1^{-/-}$Mouse}

IMPA1 ${ }^{-/-}$mice were developed in collaboration with Lexicon Genetics Inc, Houston, TX. Using a polymerase chain reaction (PCR) probe derived from the first coding exon of murine IMPA1 (Shamir et al, 2001), genomic clones were isolated by screening the $129 \mathrm{~Sv} / \mathrm{EvBrd}$-derived lambda pKOS genomic library (Zambrowicz and Friedrich, 1998). A $7.3 \mathrm{~kb}$ genomic clone spanning the first four exons was used to generate the targeting vector. An IRESLacZ/MC1-Neo reporter/selection cassette was inserted as a SfiI fragment to replace a $664 \mathrm{bp} I M P A 1$ genomic fragment that includes apart from the first seven coding nucleotides the coding region of exon 2 as well as exon 3 after yeast-mediated homologous recombination. The NotI-linearized vector was electroporated into 129Sv/EvBrd (LEX1) embryonic stem (ES) cells, and G418-fialuridine (FIAU)-resistant ES cell clones were isolated and analyzed for homologous recombination by Southern blot analysis. Targeted ES cell clones were injected into $\mathrm{C} 57 \mathrm{BL} / 6$ (albino) blastocysts, and the resulting chimeras were mated to $\mathrm{C} 57 \mathrm{BL} / 6$ (albino) females to generate animals heterozygote $(+/-)$ for the mutation. These mice were subsequently crossed to generate all three genotypes employed in the present study. PCR was used to screen genotypes by using the DNA isolated from mouse tail-biopsy samples. Primers $5^{\prime}$-ACCCTTGGCAGGAGTG CAT- $3^{\prime}$ and $5^{\prime}$-TCCTCAGATTAGCCCAGGC- $3^{\prime}$ amplified a $350 \mathrm{bp}$ band from the wild-type allele while primers $5^{\prime}$-CGATCAGGATGATCTGGAC-3' ${ }^{\prime}$ and $5^{\prime}$-GAATTCGGATC CGAACAAACG-3' amplified a $404 \mathrm{bp}$ band from the knockout allele.

\section{Measurement of Gene Expression}

Quantitative RT-PCR analysis was used to show gene expression levels of the IMPA1 and IMPA2 transcript. Total
RNA was isolated from different tissues using Trizol (Invitrogen; Carlsbad, CA) and the first-strand cDNA synthesis was performed on $0.5 \mu \mathrm{g}$ total RNA using random hexamer primers and SuperscriptII RT (Invitrogen; Carlsbad, CA). Quantitative PCR was performed on a ABIPrism 7700 cycler (Applied Biosystems; Foster City, CA) using a Taqman PCR kit. Serial dilutions of cDNA were used to generate standard curves of threshold cycles $v s$ the logarithms of concentration for $\beta$-actin and IMPA1 or IMPA2. A linear regression line calculated from the standard curves allowed determination of transcript levels in RNA samples from mice. Specific sets of primer-probe pairs were used to assay expression levels.

IMPA1 primer-probe pair spanning:

Forward primer: 5'-AGCTGTTTCAATTGGCTTCCTT-3'

Reverse primer: 5'-GCCGGTGTACATCTTATCTTCCA-3'

Probe $5^{\prime}$-TGAATAAAGAGATGGAGTTTGGAATTGTGTA

CAGCT-3' $\left[5^{\prime}\right]$ FAM [3']TAMRA

IMPA2 primer-probe pair:

Forward primer 5'-GAGGTGGCCGTGCAGTTG-3'

Reverse primer $5^{\prime}$-AGACGCGTTTTTCCTCTGTCA- $3^{\prime}$

Probe $5^{\prime}$-CCTGATGATTTGTCCCGCACGCA-3 $3^{\prime}$ [5']FAM

[3']TAMRA

$\beta$-actin primer-probe pair:

Forward primer: $5^{\prime}$-CATCTTGGCCTCACTGTCCAC-3'

Reverse primer: $5^{\prime}$-GGGCCGGACTCATCGTACT- $3^{\prime}$

Probe $5^{\prime}$-TGCTTGCTGATCCACATCTGCTGGA- $3^{\prime}$ [5']FAM

[3']TAMRA

\section{Animals}

Animals that were used for biochemical, behavioral, and pharmacological studies were individually housed and kept under 12:12-h light/dark cycle (lights on at 0600) in a temperature- and humidity-controlled room with food and water ad libitum. All experiments were conducted during the light phase of the light/dark cycle. Male mice were used for biochemical, behavioral and pharmacological studies to reduce potential variance due to the female estrus cycle. Experiments were approved by the animal care and user committee of Johnson \& Johnson Pharmaceutical Research and Development.

\section{Lethality and Rescue of IMPA1 ${ }^{-1-}$ Embryos}

Heterozygote IMPA1 ${ }^{+/-}$mice were mated and monitored daily for plugs. Females with copulation plugs were considered to be at day 0.5 of gestation. Pregnant females were killed at different times of gestation, and the embryos were dissected free of maternal tissues and genotyped by PCR using the primers described above. To administer maternal myo-inositol supplement, 2\% (w/v) myo-inositol (Sigma, St Louis, MO) was added to the drinking water of the pregnant and lactating mice.

\section{Histology}

$I M P A 1^{+/+}$and IMPA $1^{-/-}$adult male mice were perfused with $4 \%$ paraformaldehyde in phosphate-buffered saline (PBS), and brains were dissected and postfixed for $2 \mathrm{~h}$ at $4{ }^{\circ} \mathrm{C}$ in $4 \%$ paraformaldehyde in PBS. Histological examination 
was performed on $50 \mu \mathrm{m}$ cresylviolet-stained vibratome sections.

\section{IMPase activity}

IMPase activity was measured in tissue from 12-14 weeks old IMPA1 $1^{+/+}$and IMPA1 ${ }^{-/-}$male mice as described before (Cryns et al, 2007). In short hippocampus, frontal cortex and cerebellum specimens were diluted (1 mg tissue/ $81 \mu \mathrm{l}$ homogenization buffer $(50 \mathrm{mM}$ Tris- $\mathrm{HCl}, \mathrm{pH}$ 8.5; $150 \mathrm{mM} \mathrm{KCl} ; 0.5 \mathrm{mM}$ EDTA); and $0.1 \mathrm{mM}$ EGTA)). Tissue samples were sonicated for $10 \mathrm{~s}$, at $4^{\circ} \mathrm{C}$. The reaction mixture (final volume, $105 \mu \mathrm{l}$ ) contained the following components: $40 \mu \mathrm{l}$ homogenization buffer, $45 \mu \mathrm{l}$ reaction buffer $(50 \mathrm{mM}$ Tris- $\mathrm{HCl}, \mathrm{pH} 7.8 ; 250 \mathrm{mM} \mathrm{KCl}$; and $3 \mathrm{mM}$ $\mathrm{MgCl}_{2}$ ), $5 \mu \mathrm{l}$ inositol-1-phosphate $0.7 \mathrm{mM}$, and $5 \mu \mathrm{l}$ crude homogenate. In order to distinguish IMPase activity from non-specific phosphatases, the reaction was carried out in the presence and absence of $30 \mathrm{mM} \mathrm{LiCl}$. Incubation was carried out for $30 \mathrm{~min}$ at $37^{\circ} \mathrm{C}$. The reaction was stopped by mixing with $100 \mu \mathrm{l}$ color reagent (mix of $5 \mathrm{ml} 4.2 \%$ ammonium molybdate (prepared in $5 \mathrm{~N} \mathrm{HCl}$ ) and $15 \mathrm{ml}$ $0.2 \%$ Malachite Green (Sigma, St Louis, MO) in water). On the day of use $0.1 \%$ Tween 20 was added. Inorganic phosphate liberated from inositol-1-phosphate was quantified spectrophotometrically at $620 \mathrm{~nm}$. The enzyme activity was calculated as the difference between the values in absence minus the activity in the presence of LiCl. Enzyme activity was calculated per milligram protein assayed by the Bradford assay (Bio-Rad, Hercules, CA). The activity in each specimen was measured in two separate experiments, each time in triplicate.

\section{Gas Chromatographic Measurement of Inositol Levels}

Inositol levels were measured in hippocampus, frontal cortex, and cerebellum specimens, derived from 12-14 weeks old $I M P A 1^{+/+}$and IMPA1 $1^{-1-}$ male mice as well as 13.5-day-old IMPA1 $1^{+/+}$and IMPA1 $1^{-/-}$embryos. Free inositol levels were analyzed as trimethylsilyl derivatives by gas chromatography, as described previously (Shapiro et al, 2000) with minor modification. Samples of tissue were extracted in $0.5 \mathrm{ml}$ of boiling water containing $400 \mu \mathrm{g}$ mannitol for $5 \mathrm{~min}$, the denatured tissue was centrifuged $\left(1000 \mathrm{~g}, 10 \mathrm{~min}, 4^{\circ} \mathrm{C}\right)$, and $250 \mu \mathrm{l}$ supernatant was lyophilized $(3 \mathrm{~h}$, Speed Vac SC 110); silylation of the dried sample was carried out with $200 \mu \mathrm{l}$ of a mixture of pyridine: bis(trimethylsilyl)-trifluoroacetamide:chlorotrimethylsilan 10:2:1 (by vol) for $24 \mathrm{~h}$ at room temperature. One-microliter aliquots were chromatographed on a capillary column (RTX-1, 15 m, $0.25 \mathrm{~mm}$ ID, Restek). Quantification was performed with the use of trimethylsilyl (TMS) derivatives of standard myo-inositol and with mannopyranoside as an internal standard. The results are the means of at least two aliquots from each sample.

\section{Behavioral Analysis}

Different batches of IMPA1 $1^{+/+}$and IMPA1 $1^{-/-}$male littermates with age ranging from 12- to 20 -week-old were used in the open-field test and forced-swim tests.
Open-field test. Locomotor activity was monitored using a Tru-scan ${ }^{\circ}$ system (Coulbourn instruments, Allentown, PA) under mild illumination conditions (100 lux). The animal was placed in the center of the activity-field arena, which is a transparent Perspex cage $(W \times D \times H ; 260 \times 260 \times$ $400 \mathrm{~mm}$ ) equipped with two photo-beam sensor rings to register horizontal and vertical activity. Testing lasted $60 \mathrm{~min}$ and distance traveled was measured in 5-min time bins. The relative time spent in the center $(=$ total time spent in the center/total movement time, in \%) and relative distance traveled in the center of the open-field arena ( = total distance traveled in the center of the open-field/ total distance traveled, in \%) were analyzed as a measure for anxiety-like behavior.

Forced-swim test. Mice were placed in a cylinder (diameter $10 \mathrm{~cm}$ ), filled with water to a height of $10 \mathrm{~cm}$ (such that the mouse could not touch the bottom or rim of the cylinder at any point) and a temperature of $25 \pm 1^{\circ} \mathrm{C}$. Each mouse was pre-exposed to swim stress for $6 \mathrm{~min}$ on day 1 and a test session of $6 \mathrm{~min}$ was performed $24 \mathrm{~h}$ later. Total duration of immobility was measured using the Videotrack system (Viewpoint, Lyon, France).

Chronic lithium treatment. Male IMPA1 ${ }^{+/+}$and IMPA1 ${ }^{-/-}$ littermates (4-5 months old) were treated with control chow $(n=12)$ or chow containing $0.2 \%(n=12)$ lithium carbonate (Teklad, Madison, WI) for 21 days. Water was available ad libitum. During this period, body weight and daily water intake were recorded. After 21 days, open-field testing and forced-swim testing were performed. Data obtained from a satellite experiment on mice with a mixed C57BL/6J-129Sv/ Evbrd genetic background where chow containing $0.2 \%$ $(n=12)$ or $0.4 \%$ lithium carbonate was used, demonstrated that $0.4 \%$ lithium carbonate was highly toxic and resulted in lethality in about $50 \%$ of the mice. The chronic treatment of mice resulted in average plasma lithium levels of 0.67 $\pm 0.069 \mathrm{mM}$ (mean $\pm \mathrm{SEM})$ for the $0.2 \%$ group and $2.8 \pm 0.437$ in the $0.4 \%$ group.

\section{Pilocarpine-Induced Seizures}

IMPA1 $1^{+/+}(n=12)$ and IMPA1 ${ }^{-/-}(n=19)$ male littermates (12-14 weeks old) were injected subcutaneously with $100 \mathrm{mg} / \mathrm{kg}$ pilocarpine. A positive control group $(n=6)$ was injected with $10 \mathrm{mEq} / \mathrm{kg} \mathrm{LiCl}$ followed by pilocarpine $18 \mathrm{~h}$ later. The mice were rated for signs of seizures once every $5 \mathrm{~min}$ for $1 \mathrm{~h}$ according to a modified version of the scale used by Patel et al (1988). The scoring was as follows: $0=$ no response; $1=$ gustatory movements, and/or fictive scratching; $2=$ tremor; $3=$ head bobbing; $4=$ forelimb clonus; $5=$ rearing, clonus, and falling. In addition, the latency to attain rearing, clonus and falling (a score of 5) was recorded for each mouse (Kofman et al, 1993). A welltrained observer blind to the treatment groups scored the mice.

\section{Lethality of Inositol-Deficient Food}

In $I M P A 1^{-/-}$mice, we hypothesized that the organism would be dependent on exogenous inositol. Mice chow was prepared as per Shaldubina et al (2006b) and $I M P A^{-1-}$ mice 
were fed the inositol deficient chow or identical chow with inositol for 21 days.

\section{Statistical Analysis}

A student's $t$-test was used to compare IMPase activity, inositol levels and the latency to seizure following pilocarpine administration between the two genotypes. For the behavioral analysis, one-way analysis of variance (ANOVA) (genotype) and two-way ANOVA (genotype $\times$ time effect) followed by all pairwise multiple comparison with the Holm Sidak method was performed. In case data were not normally distributed, a $\log _{e}$ transformation was performed.

\section{RESULTS}

\section{Generation of the IMPA1 ${ }^{-/-}$Mouse}

The IMPA1 mouse gene contains nine exons. Homologous recombination resulted in deletion of the major part of the coding region of the first coding exon (exon 2), and exon 3, with insertion of the LacZ reporter gene and disruption of the open reading frame (Figure $1 \mathrm{a}$ and $\mathrm{b}$ ). Correct targeting in ES cells was confirmed by Southern blot analysis (results not shown) and loss of the wild-type IMPA1 allele was confirmed by PCR analysis (Figure 1c). Expression of IMPA1 transcription was analyzed by RT-QPCR using a primer-probe pair spanning exon 7 and exon 8 and located downstream of the deletion. Using this primer-probe pair, a transcript at low level was observed in IMPA1 ${ }^{-/-}$embryos, indicating that a residual, truncated IMPA1 transcript is present in the IMPA1 ${ }^{-1-}$ embryos (Figure 1d). To look for potential compensatory mechanisms, IMPA2 mRNA levels were analyzed in three different brain regions by RT-QPCR using a primer-probe pair spanning exon 1 and exon 2, however, no changes in expression level between IMPA1 $1^{+/+}$ and IMPA1 $1^{-/-}$mice were found (Figure 1e).

\section{Lethality of IMPA1 ${ }^{-/-}$Embryos}

Genotype analysis of 4-week-old offspring derived from heterozygote IMPA1 $1^{+/-} \times I M P A 1^{+/-}$breeding revealed that only $2 \%$ instead of the expected $25 \%$ of $I M P A 1^{-1-}$ mutants could be recovered at that time point (Table 1a). To determine whether and when IMPA1 ${ }^{-I}$ mice died in utero, embryos derived from IMPA1 $1^{+/-} \times I M P A 1^{+/-}$breeding were collected at different embryonic stages and genotyped. Of the 97 embryos analyzed at day 9.5 post coitum (p.c.), there were $19 \mathrm{IMPA1}^{+/+}, 38 \mathrm{IMPA1} 1^{+/-}$and $16 \mathrm{IMPA} 1^{-/-}$ embryos, approximating the expected $1 / 2 / 1$ genotype ratio (Table 1a). At day 10.5 p.c., a distorted genotype ratio was observed since there were $19 \mathrm{IMPA1} 1^{+/+}, 22 \mathrm{IMPA1} 1^{+/-}$, and only two IMPA1 ${ }^{-1-}$ embryos. This indicated that the majority of the homozygous mutant embryos died between days 9.5 and 10.5 p.c. as evident by the concordant occurrence of high numbers of resorbed embryos (Table 1a). At day 9.5 p.c., histological analysis did not reveal any obvious abnormalities in the IMPA $1^{-1-}$ embryos (results not shown). The few IMPA1 ${ }^{-/-}$mice that reached adulthood did not show any overt abnormalities apart from signs of hyperactivity or stereotypy in the home cage, that is, the mutant mice frequently jumped persistently up and down against the side of the cage. The presence of the IMPA1 transcript in IMPA1 ${ }^{+/+}$embryos at and around day 10.5 p.c. was shown by RT-QPCR (Figure 1f).

\section{Rescue of Embryonal Lethality}

To study the possibility that the embryonic lethality occurred as a consequence of inositol depletion, the effect of maternal dietary inositol supplementation was evaluated. The drinking water of the IMPA1 ${ }^{+/-}$females, mated with IMPA $1^{+/-}$males, was supplemented with myo-inositol $(2 \%$ $w / v)$ starting at the day of impregnation until weaning 3 weeks after birth. At the time of weaning, the ratio of IMPA1 $1^{+/+} / I M P A 1^{+/-} / I M P A 1^{-/-}$embryos was approximately $1 / 2 / 1$, indicating that prenatal inositol supplementation prevented embryonic lethality of the $I M P A 1^{-/-}$mice (Table 1b). No abnormal mortality rate was observed in the $I M P A 1^{-/-}$offspring once inositol supplementation was discontinued after weaning.

Overall inositol-supplemented IMPA1 ${ }^{-/-}$mice were indistinguishable from the IMPA1 $1^{+/+}$littermates in terms of development and fertility. Similarly, to the non-

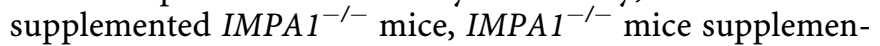
ted with inositol mutants also showed signs of hyperactivity and stereotypy in the home cage. Full necropsy and histological examination did not reveal any apparent developmental abnormalities between inositol-rescued $I M P A 1^{-/-}$and $I M P A 1^{+/+}$mice. Similarly, serial histological sections through the brain did not show obvious difference in cytoarchitecture, appearance of neurons in the different regions or a change in glia to neuron ratio (Figure 2).

IMPA $1^{-/-}$mice fed for 21 days with inositol deficient food (Shaldubina et al, 2006b) showed no lethality or toxicity compared with $I M P A 1^{-1-}$ mice on regular chow.

\section{IMPase Activity and Inositol Levels}

IMPase activity and inositol levels were measured in the frontal cortex, hippocampus and in the cerebellum of 12- to 14-week-old IMPA1 ${ }^{+/+}$and IMPA1 $1^{-/-}$mice supplemented with myo-inositol until weaning. Hippocampal, frontal cortex, and cerebellar IMPase activity were significantly decreased by 65,40 , and $40 \%$, respectively, in the IMPA $1^{-/-}$ mice compared with IMPA1 ${ }^{++}$mice (Table 2). No difference was observed in inositol levels between $I M P A 1^{+/+}$and IMPA1 $1^{-/-}$mice in the hippocampus, frontal cortex, or in the cerebellum (Table 2).

In 13.5-day-old $I M P A 1^{-1-}$ embryos without inositol supplementation, inositol levels were found to be significantly reduced by $39 \%$ (Table 2 ).

\section{Behavioral Analysis}

To study the possible involvement of IMPA1 in complex behaviors related to affective disorders, we monitored the behavior of inositol-rescued male IMPA1 ${ }^{-1-}$ mice. General locomotor, exploratory and anxiety-like behavior was assessed in the open-field test. In the IMPA1 $1^{-1-}$ mice, the total distance traveled $\left(\mathrm{F}_{(1,22)}=4.60, p<0.05\right)$ and the total time moving $\left(\mathrm{F}_{(1,22)}=5.13, p<0.05\right)$ was significantly higher compared with IMPA1 ${ }^{+/+}$mice (Table 3 ). The observed 

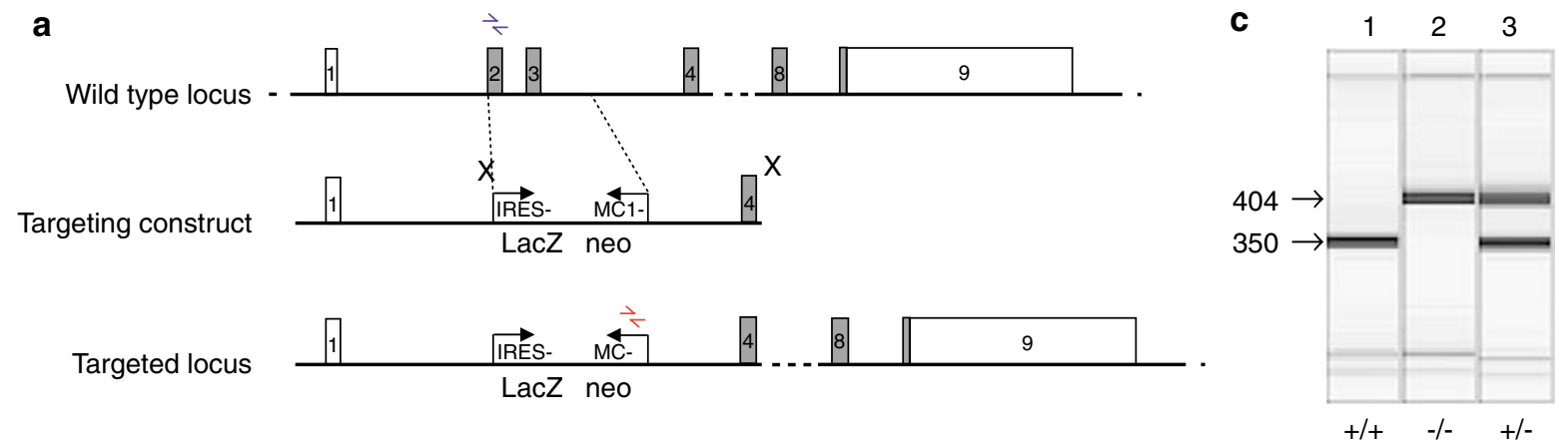

\section{b MA..DPWQECMDYAVILARQAG \\ $\uparrow$ \\ Disruption of ORF}

d

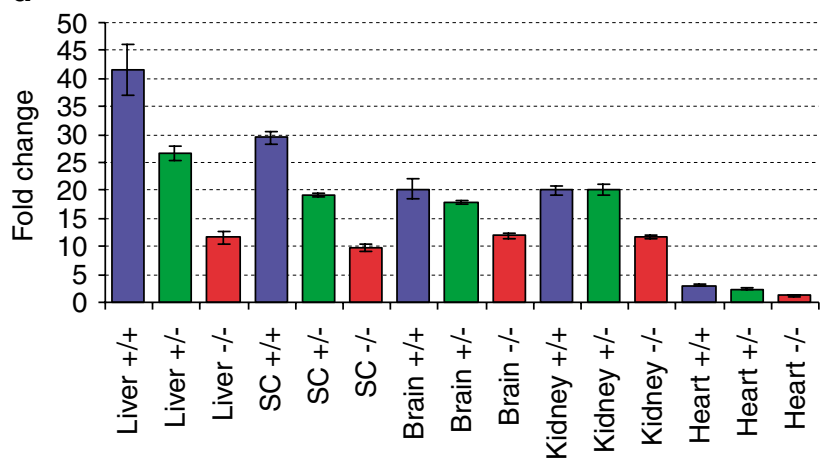

e

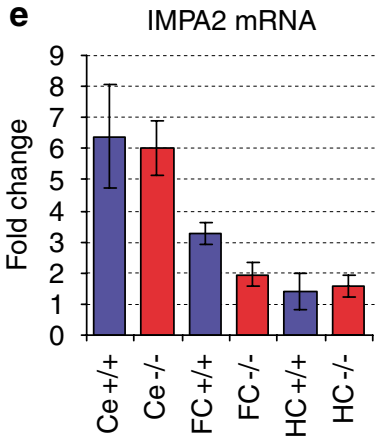

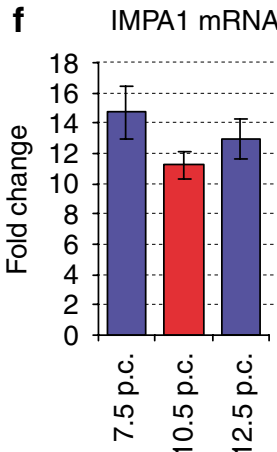

Figure I Targeted disruption of the IMPA I gene. (a) Structure of the wild-type locus, targeting vector and recombinant locus. Boxes represent the known exons, the non-coding and coding regions are indicated in white and gray, respectively (a). A lambda pKOS-based targeting construct was generated by replacing most of the coding regions of exon 2 and exon 3 by the IRESLacZ/MCI-Neo reporter/selection cassette and interrupting the open reading frame (site of interruption shown in panel b). Blue and red arrows indicate position of the PCR primers used for genotyping the wild type and targeted allele, respectively. (c) The wild type and targeted allele give a 350 and 404 bp PCR product, respectively, and identify $|M P A|^{+9+}$ (lane I), IMPA| ${ }^{+1-}$ (lane 3), and $|M P A|^{-1-}$ (lane 2) animals. (d) Expression of the IMPAI transcript in liver, spinal cord (SC), brain, kidney, and heart was decreased in the $|M P A|^{-l-}$ mouse as determined by quantitative RT-PCR, however, a residual transcript was still present. Values expressed are average $(n=3)$ relative expression levels after normalization to $\beta$-actin. (e) Expression of the IMPA2 transcript was comparable in cerebellum (CeB), frontal cortex (FC) and hippocampus (HC) in $|M P A|^{+1+}$ and $|M P A|^{-1-}$ mice as determined by quantitative RT-PCR. Values expressed are average $(n=3)$ relative expression levels after normalization to $\beta$-actin. (f) Expression of the IMPAI transcript was detected at comparable levels in $|M P A|^{+1+}$ embryos at 7.5, $\mid 0.5$ and $\mid 2.5$ days p.c. Values expressed are average $(n=5)$ relative expression levels after normalization to $\beta$-actin.

Table I Lethality and Rescue of $|M P A|^{-1-}$ Embryos

Embryos

\section{Resorption}

(a)

9.5 p.c.

10.5 p.c.

13.5 p.c.

Newborn

(b) increase in total distance and total time traveled was, however, not reflected in an increased number of moving episodes $\left(\mathrm{F}_{(1,22)}=1.96, p=0.16\right)($ Table 3$)$. In the IMPA1 $1^{-/ \text {- }}$ mice, the relative distance traveled in the center was significantly lower compared with $I M P A 1^{+/+}$mice $\left(\mathrm{F}_{(1,22)}=9.18, p<0.01\right)$, while the relative time traveled in the center was not different between the genotypes $\left(\mathrm{F}_{(1,22)}=0.17, p=0.68\right)$ (Table 3$)$. There was no difference 
between genotypes in the relative distance and time traveled in the margin (respectively, $\mathrm{F}_{(1,22)}=3.66, p=0.07$ and $\left.\mathrm{F}_{(1,22)}=0.17, p=0.68\right)$. In addition, a highly significant increased number of rearings was observed in the IMPA $1^{-1-}$ mice $\left(\mathrm{F}_{(1,22)}=12.29, p<0.01\right)$ (Table 3$)$.

To evaluate the possibility that the observed hyperactivity in the open-field test is due to inositol depletion in the adult IMPA $1^{-1-}$ mice, adult mice were dietary supplemented for 3 weeks with inositol (2\%) via the drinking water prior to testing in the open-field test. Hyperactivity was observed under these experimental conditions as well. In the inositol-
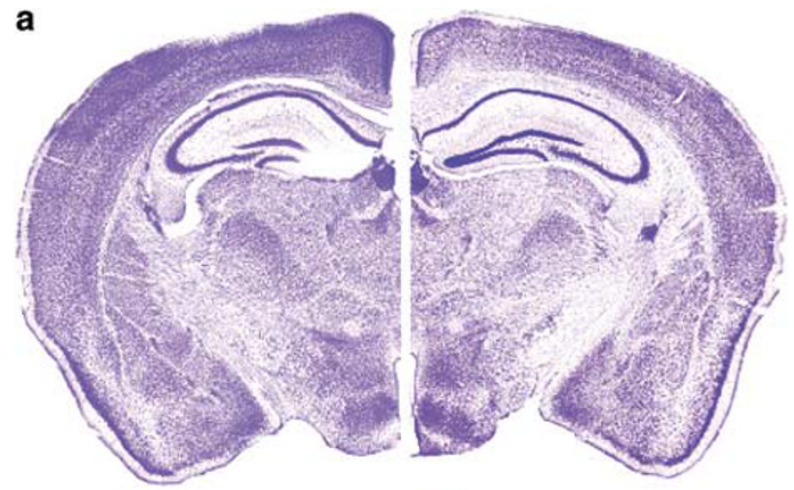

b
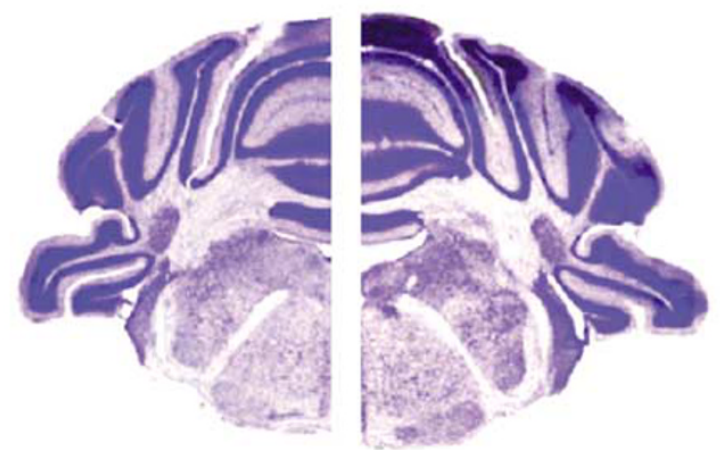

IMPA $1^{+/+}$

IMPA1 $^{-/-}$

Figure 2 Histology of the brain of $|M P A|^{-/-}$and $|M P A|^{+/+}$mice. Cresyl violet staining of $50 \mu \mathrm{m}$ vibratome section of $\mathrm{IMPA}^{+/+}$(left) and $\mathrm{IMPA}^{-1-}$ mouse-derived brain (right) at the level of (a) the cerebrum (Bregma $-2.56 \mathrm{~mm}$ ) and (b) cerebellum (Bregma $-10.30 \mathrm{~mm}$ ). supplemented IMPA1 $1^{-/-}$mice, the distance traveled $\left(\mathrm{F}_{(1,286)}=37.39, \quad p<0.001\right)$ and the time moving $\left(\mathrm{F}_{(1,286)}=35.07, p<0.001\right)$ was significantly higher compared with $I M P A 1^{+/+}$mice (Table 4 , Figure $3 \mathrm{a}$ and $\mathrm{b}$, respectively). Post hoc analyses across the 5-min time bins revealed that the increase in motor activity in the $I M P A 1^{-/-}$ mice was evident in the final $35 \mathrm{~min}$ of the $60-\mathrm{min}$ observation (Figure 3 ). With time passing, both the distance traveled $\left(\mathrm{F}_{(1,276)}=16.74, p<0.001\right)$ as well as the time moving $\left(\mathrm{F}_{(1,276)}=16.07, p<0.001\right)$ decreased (Figure 3$)$. Again, the observed increase in distance and time traveled was not reflected in the total increased number of movement episodes $\left(\mathrm{F}_{(1,21)}=1.67, p=0.210\right) \quad$ (Table 4). No difference between genotypes was observed in the relative distance and time traveled both in the center as well as in the margin (Table 4) arguing against an altered

Table 3 Performance of Male IMPA++ and IMPA $\left.\right|^{-1-}$ Mice in the Open-Field and Forced-Swim Tests

\begin{tabular}{|c|c|c|}
\hline Parameter & $\mid M P A I^{+/+}$ & IMPAII- \\
\hline \multicolumn{3}{|l|}{ Open-field test } \\
\hline Total distance traveled $(\mathrm{cm})$ & $6256 \pm 737$ & $8808 \pm 934 *$ \\
\hline Total time in motion (s) & $1697 \pm 136$ & $2101 \pm 115^{*}$ \\
\hline Total move episodes (no.) & $1017 \pm 63$ & $1121 \pm 36$ \\
\hline Relative distance traveled in the center (\%) & $19.6 \pm 1.8$ & $12.5 \pm 1.5$ *** \\
\hline Relative time spent in the center $(\%)$ & $12.8 \pm 2.0$ & $11.7 \pm 1.8$ \\
\hline Relative distance traveled in the margin (\%) & $62.5 \pm 9.7$ & $70.9 \pm 11.7$ \\
\hline Relative time traveled in the margin (\%) & $87.2 \pm 2.0$ & $88.2 \pm 1.8$ \\
\hline Rearing (no.) & $133 \pm 2 \mid$ & $287 \pm 38 * * *$ \\
\hline \multicolumn{3}{|l|}{ Forced-swim test } \\
\hline Immobility time (s) 0- | 80 & $73.2 \pm 7.6$ & $20.3 \pm 7.6$ ****** \\
\hline Immobility time (s) $180-360$ & $99.6 \pm 8.8$ & $54.7 \pm 15.0 *$ \\
\hline Total immobility time (s) & $173 \pm 15$ & $75 \pm 22 * * *$ \\
\hline
\end{tabular}

Results are mean \pm SEM; $|M P A|^{+/+}(n=\mid 2) ;|M P A|^{-1-}(n=12)$ in OFT and $|M P A|^{+/+}(n=12) ;|M P A|^{-1-}(n=\mid 1)$ in FST.

Single, double, and triple asterisks indicate a significant difference $p<0.05$, $p<0.01$, and $p<0.00 \mathrm{I}$, respectively, between $|\mathrm{MPA}|^{+/+}$and $|\mathrm{MPA}|^{-1-}$ mice.

Table 2 IMPase and Inositol Levels

\begin{tabular}{|c|c|c|c|c|}
\hline & $\mid M P A I^{+/+}$ & IMPAII-- & $t$-value & p-value \\
\hline \multicolumn{5}{|c|}{ IMPase activity (nmol/mg min) } \\
\hline Hippocampus & $3.10 \pm 0.45(n=17)$ & $1.08 \pm 0.15(n=8)$ & $t=2.09$ & $p<0.00$ I* \\
\hline Frontal cortex & $1.20 \pm 0.11 \quad(n=5)$ & $0.70 \pm 0.13(n=3)$ & $t=2.44$ & $p=0.03^{*}$ \\
\hline Cerebellum & $1.07 \pm 0.13(n=4)$ & $0.64 \pm 0.01 \quad(n=3)$ & $t=2.57$ & $p=0.03 *$ \\
\hline Frontal cortex & $4.86 \pm 0.39(n=9)$ & $4.96 \pm 0.50(n=8)$ & $t=2.10$ & $p=0.88$ \\
\hline Cerebellum & $6.12 \pm 0.38(n=10)$ & $5.67 \pm 0.38(n=10)$ & $t=2.01$ & $p=0.41$ \\
\hline Embryos I3.5 p.c. & $3.03 \pm 0.26(n=9)$ & $1.85 \pm 0.38(n=10)$ & $t=2.20$ & $p=0.04 *$ \\
\hline
\end{tabular}


Table 4 Performance of Male IMPA++ and IMPA $\left.\right|^{-1-}$ Mice in the Open-Field Test Supplemented for 3 Weeks with Inositol (2\%) of Adulthood

\begin{tabular}{|c|c|c|}
\hline Parameter & $\mid M P A I^{+/+}$ & $\mid M P A I^{-I-}$ \\
\hline \multicolumn{3}{|l|}{ Open field test } \\
\hline Total distance traveled $(\mathrm{cm})$ & $5297 \pm 534$ & $10842 \pm 1348 * * * *$ \\
\hline Total time in motion (s) & $1582 \pm 132$ & $2272 \pm 11 \mid * * * *$ \\
\hline Total move episodes (no.) & $1019 \pm 67$ & $1114 \pm 42$ \\
\hline Relative distance traveled in the center (\%) & $19.7 \pm 2.0$ & $\mid 8.1 \pm 2.0$ \\
\hline Relative time spent in the center (\%) & $14.0 \pm 2.9$ & $18.4 \pm 2.8$ \\
\hline Relative distance traveled in the margin (\%) & $64.0 \pm 2.8$ & $58.1 \pm 4.3$ \\
\hline Relative time spent in the margin (\%) & $86.0 \pm 2.9$ & $81.6 \pm 2.8$ \\
\hline Rearing & $79 \pm 14$ & $328 \pm 49 * * * * *$ \\
\hline
\end{tabular}

Results are mean \pm SEM; $|M P A|^{+/+}(n=\mid 2) ;|M P A|^{-1-}(n=\mid I)$.

Triple asterisk indicates a significant difference of $p<0.00 \mid$ between $|M P A|^{+/+}$ and $|M P A|^{-1-}$ mice.

anxiety-related phenotype in the IMPA ${ }^{-/-}$mice. Also, in the inositol-supplemented IMPA1 ${ }^{-/-}$mice, the number of rearings was increased $\left(\mathrm{F}_{(1,21)}=32.28, p<0.001\right)$ (Table 4, Figure 3).

Depression-related behavior was assessed in the forcedswim test. IMPA1 $1^{-1-}$ mice exhibited a decreased total immobility time compared with $I M P A 1^{+/+}$littermates both in the first (in average \pm SEM: $20.3 \pm 7.6 \mathrm{~s}$ in $I M P A 1^{-1-}$ and $73.2 \pm 7.6 \mathrm{~s}$ in IMPA $1^{+/+}$, genotype effect $\mathrm{F}_{(1,43)}=53.24$, $p<0.001$ ) as well as the last $3 \mathrm{~min}$ of the test (in average \pm SEM: $54.7 \pm 15.0 \mathrm{~s}$ in $I M P A 1^{-/-}$and $99.6 \pm 8.8 \mathrm{~s}$ in $I M P A 1^{+/+}$, genotype effect $\left.\mathrm{F}_{(1,43)}=10.15, p<0.01\right)$ (Table 3).

\section{Effect of Chronic Lithium Treatment on Behavior}

IMPA $2^{+/+}$and IMPA2 $2^{-/-}$mice were chronically treated with lithium by feeding the mice chow containing $0.2 \%$ lithium carbonate. Over time, a significant effect on body weight was observed (time effect: $\mathrm{F}_{(8,336)}=5.56, p<0.01$ ) as a consequence of the reduction in body weight induced by the $0.2 \%$ lithium carbonate treatment (time $\times$ treatment effect: $\left.F_{(8,336)}=13.52, p<0.001\right)$ which was independent of the genotype of the animals (genotype effect: $\mathrm{F}_{(1,42)}=0.00$, $p=0.96$ ) (Figure 4). Feeding the animals with lithium carbonate also resulted in a significant effect on water intake (treatment effect: $\mathrm{F}_{(7,294)}=17.69, p<0.001$ ), which was independent of the genotype (treatment $\times$ genotype effect: $\left.F_{(7,294)}=0.74, p=0.64\right)$. Post hoc analysis indicated that treating the animals with $0.2 \%$ lithium carbonate significantly increased water intake from day 7 onwards (Figure 4).

When subjected to the open-field test, after 21-day treatment, the total distance traveled was still significantly higher in the IMPA1 $1^{-/-}$mice compared with IMPA1 ${ }^{+/+}$ mice (genotype effect: $F_{(1,42)}=22.41, p<0.001$ ) (Figure 4). No effect of the lithium carbonate treatment was observed (treatment effect: $\mathrm{F}_{(1,42)}=0.68, p=0.41$ ). In addition, a highly significant increased number of rearings was observed in the IMPA $1^{-/-}$mice $\left(\mathrm{F}_{(1,42)}=32.71, p<0.001\right)$, while again no effect of the treatment was observed (treatment effect:
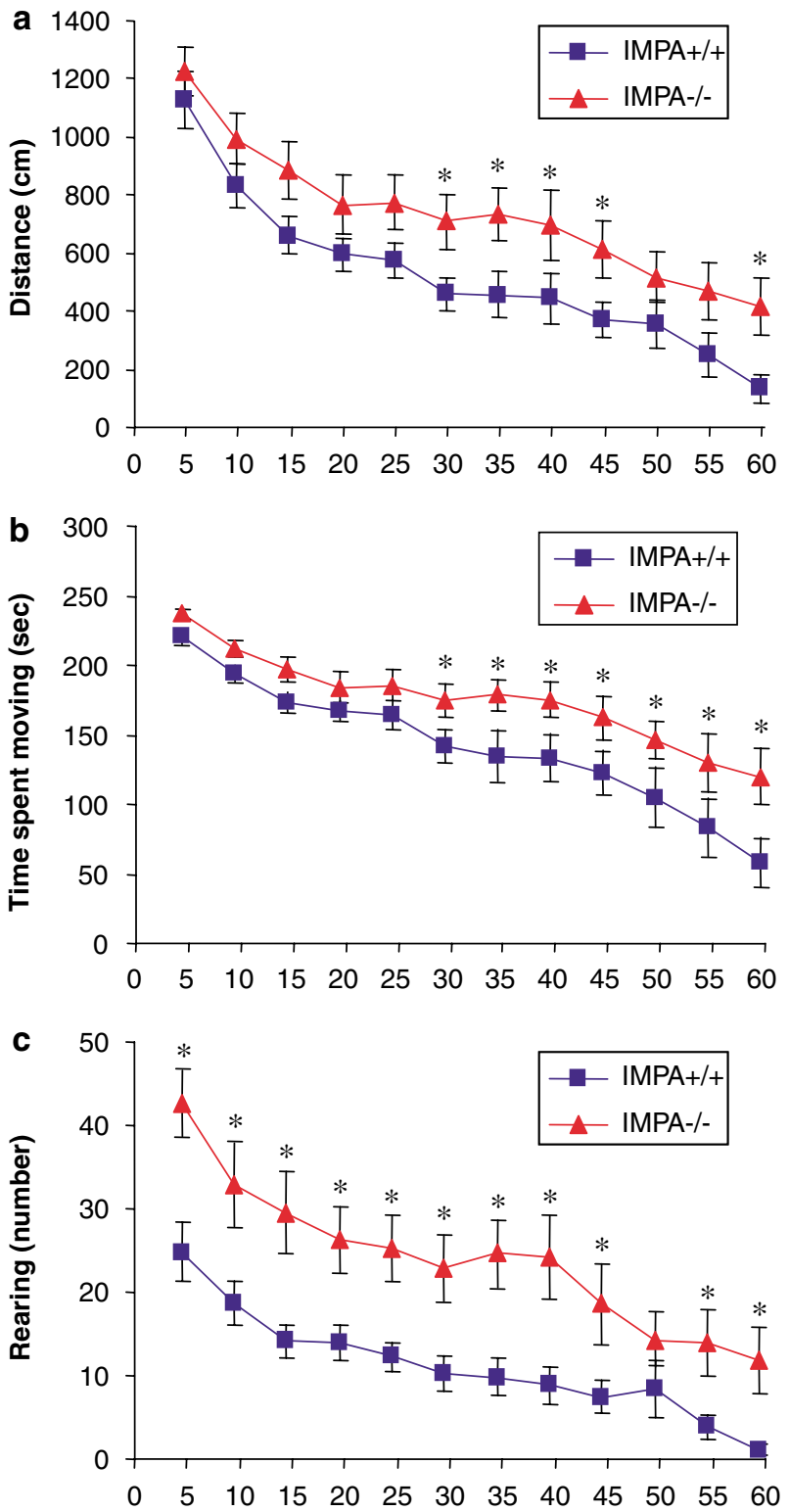

Figure 3 Behavioral testing after inositol supplementation. Locomotor activity (mean \pm SEM) measurement in open-field testing (over 12 5-bins) indicated that (a) IMPA $\left.\right|^{-1-}$ mice traveled a larger distance than IMPA ${ }^{+1+}$ mice and (b) IMPA| ${ }^{-1-}$ mice spent more time moving than $|M P A|^{+/+}$ mice. (c) Rearing in IMPA ${ }^{-1-}$ mice was significantly higher than that in $|\mathrm{MPA}|^{+1+}$ mice. ${ }^{*} p<0.05|\mathrm{MPA}|^{+/+}$vs $|\mathrm{MPA}|^{-1-}$ mice.

$\mathrm{F}_{(1,42)}=1.81, p=0.19$ ) (Figure 4). In the forced-swim test, $I M P A 1^{-/-}$mice again exhibited a decreased total immobility time compared with IMPA1 $1^{+/+}$littermates both in the first (in average \pm SEM: $21.1 \pm 5.1 \mathrm{~s}$ in $I M P A 1^{-/-}$and $72.2 \pm 4.8 \mathrm{~s}$ in $I M P A 1^{+/+}$, genotype effect: $\left.\mathrm{F}_{(1,44)}=53.24, p<0.001\right)$ as well as the last $3 \mathrm{~min}$ of the test (in average $\pm S E M$ : $56.1 \pm 9.8 \mathrm{~s}$ in IMPA $1^{-/-}$and $99.0 \pm 9.2 \mathrm{~s}$ in $I M P A 1^{+/+}$, genotype effect: $\left.F_{(1,43)}=10.15, p<0.01\right)$. No effect of the treatment was observed in both the first (in average \pm SEM: $46.5 \pm 4.9 \mathrm{~s}$ in normal chow and $46.8 \pm 4.9 \mathrm{~s}$ in $0.2 \%$ lithium carbonate, treatment effect: $\left.\mathrm{F}_{(1,44)}=0.00, p=0.97\right)$ as well as the last $3 \mathrm{~min}$ of the test (in average \pm SEM: $77.1 \pm 9.4 \mathrm{~s}$ in normal chow and $77.9 \pm 9.6 \mathrm{~s}$ in $0.2 \%$ lithium carbonate, treatment effect: $\left.\mathrm{F}_{(1,43)}=0.00, p=0.95\right)$. 

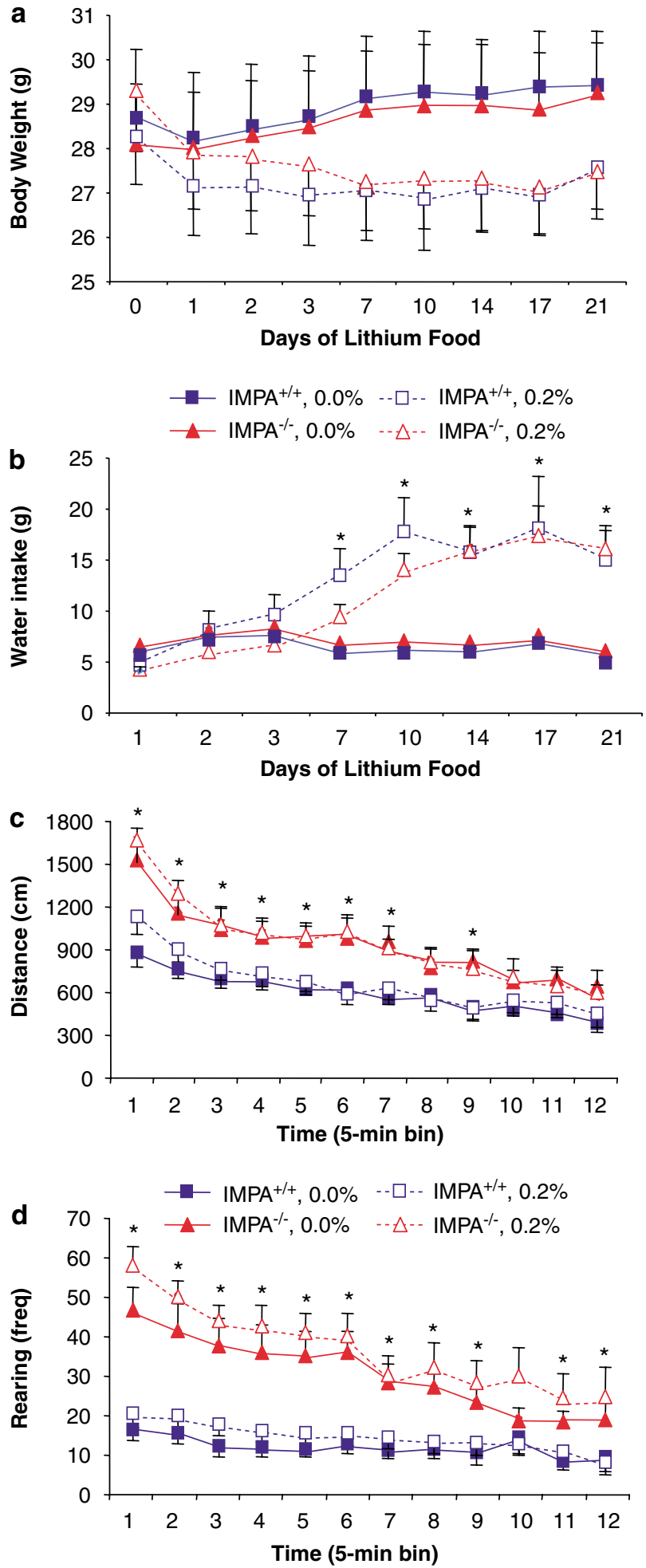

Figure 4 Behavioral testing after chronic lithium treatment. Chronic lithium treatment over 21 days resulted in a significant decrease in body weight, which was independent of the genotype (a) and a significant increase in water intake, which again was independent of the genotype (b). Open-field testing (over 12 5-bins) indicated that (c) IMPAI ${ }^{-1-}$ mice traveled a larger distance than $|M P A|^{+/+}$mice, while no effect of the treatment was observed. (d) Rearing in $|M P A|^{-1-}$ mice was significantly higher than that in $|M P A|^{+1+}$ mice, while no effect of the treatment was observed. ${ }^{*} \mathrm{p}<0.05|\mathrm{MPA}|^{+/+}$vs $|\mathrm{MPA}|^{-1-}$ mice.

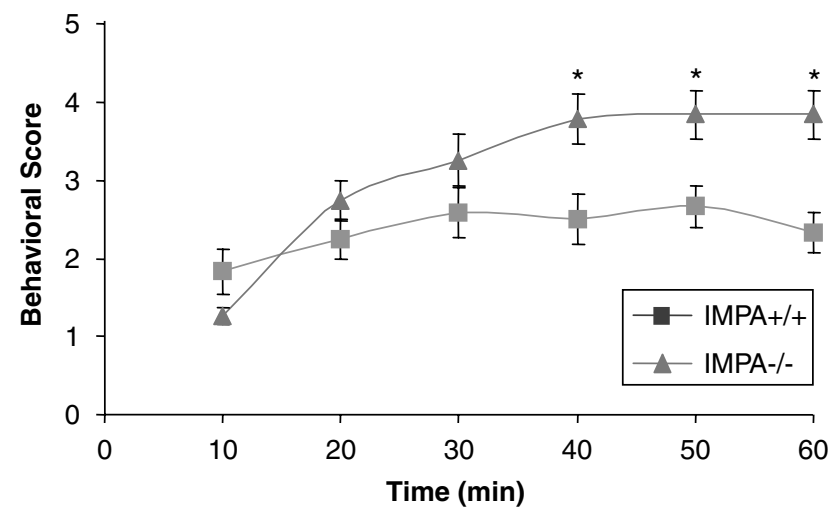

Figure 5 Behavioral response of $|\mathrm{MPA}|^{+/+}$and $|\mathrm{MPA}|^{-1-}$ mice to $100 \mathrm{mg} / \mathrm{kg}$ pilocarpine. $|\mathrm{MPA}|^{+1+}$ and $|\mathrm{MPA}|^{-1-}$ mice were injected with $100 \mathrm{mg} / \mathrm{kg}$ pilocarpine and seizures were scored once every $5 \mathrm{~min}$ for $\mathrm{I} \mathrm{h}$ according to the following scale: $0=$ no response; $I=$ gustatory movements and/or fictive scratching; $2=$ tremor; $3=$ head bobbing; $4=$ forelimb clonus; $5=$ rearing, clonus and falling. ${ }^{*} p<0.05$ (LSD post hoc test; a difference between genotypes in the same time bin).

\section{Pilocarpine Sensitivity}

Administration of a subconvulsive dose of $100 \mathrm{mg} / \mathrm{kg}$ pilocarpine did not cause limbic seizures in $I M P A 1^{+/+}$ mice $(n=12)$, while $63 \%(12 / 19)$ of $I M P A 1^{-/-}$mice went into seizures similar to the $83 \%(5 / 6)$ of the $I M P A 1^{+/+}$mice that were pretreated with lithium (positive control group). Latency to seizure onset in IMPA1 $1^{-1-}$ mice was similar to that in the positive control group (mean \pm SEM: $30 \pm 5$ min in IMPA1 ${ }^{-f-}$ and $47 \pm 6 \mathrm{~min}$ in the positive control group; T-test: $t=2.2, \mathrm{df}=11, p=0.09)$. The difference in pilocarpine-induced seizure sensitivity between genotypes was also evident from the behavioral scores after administration of $100 \mathrm{mg} / \mathrm{kg}$ pilocarpine (total score \pm SEM: $3.12 \pm 0.41$ in $I M P A 1^{-/-}$and $2.30 \pm 0.12$ in $I M P A 1^{+/+}, \mathrm{F}_{(1,29)}=6.71$, $p<0.0001$ ) (Figure 5). The maximal average behavioral score reached by $I M P A 1^{-1-}$ mice was $3.84 \pm 0.32$ SEM (forelimb clonus) and by IMPA1 ${ }^{+/+}$mice was $2.67 \pm 0.27$ SEM (head bobbing). In addition to a significant effect of genotype $\left(\mathrm{F}_{(1,29)}=6.71, p=0.014\right)$, a significant effect of time $\left(\mathrm{F}_{(5,145)}=19.16, \quad p<0.0001\right)$, and genotype $\times$ time interaction $\left(\mathrm{F}_{(5,145)}=6.64, \quad p<0.0001\right) \quad$ was observed (Figure 5).

\section{DISCUSSION}

Lithium salts are the most widely used treatment for bipolar disorder (Goodwin and Jamison, 1990). At therapeutically relevant concentrations, they inhibit a group of phosphomonoesterases (inositol monophosphate phosphatase, inositol polyphosphate phosphatase, fructose 1,6-bisphosphate 1-phosphatase, and bisphosphate nucleotidase), the metabolic enzyme phosphoglucomutase, and glycogen synthase kinase-3 (GSK3). Despite 50 years of clinical use and intensive research, the molecular targets through which lithium exerts its therapeutic effects are still not defined. In the present work, we characterized the phenotypic effects of a dysfunctional IMPA1 gene in mice focusing on in vivo physiological functions of IMPA1, in 
general, and more specifically, its potential role as a molecular target in mediating lithium-dependent physiologic effects.

The IMPA1 $1^{-1-}$ mice died in utero between days 9.5 and 10.5 p.c. which demonstrates the importance of IMPA1 in early embryonic development. The underlying developmental cause is currently under study, but the data presented suggest that depletion of inositol is the physiological cause of the observed lethality. Markedly reduced inositol levels were observed in the IMPA1 ${ }^{-/-}$embryos at day 13.5 p.c., and inositol supplementation in the pregnant mothers rescued the lethality of the IMPA $1^{-1-}$ embryos. Inositol has been shown before to be required for embryonic development (Chau et al, 2005). Deletion of the sodium myo-inositol cotransporter-1 (SMIT), a transporter responsible for importing inositol into cells, caused lethality of newborn pups due to a developmental abnormality of the peripheral nerves apparent at day 18.5 p.c. Also, in this model, lethality was rescued by supplementation of the mothers with inositol (Chau et al, 2005). The finding that in IMPA1 $1^{-/-}$mice, lethality occurred before day 10.5 p.c. suggests that in early embryonic development, the de novo synthesis of inositol and/or recycling in the PI cycle, mediated via IMPA1 is a more critical source of intracellular inositol than import from the extracellular space. Rescue of lethality in the $I M P A 1^{-1-}$ mice by inositol supplementation, however, indicates that increased import from the extracellular space can compensate for the impaired de novo synthesis in the developing embryo.

IMPA $1^{-/-}$mice exhibited an increased sensitivity to pilocarpine-induced seizures. Multiple rodent studies have shown that lithium treatment causes a sensitization to pilocarpine-induced seizures (Honchar et al, 1983; Kofman and Belmaker, 1993). Moreover, this enhanced sensitivity was shown to be reversed by replenishment of myo-inositol and not by its stereoisomer chiro-inositol that does not enter the PI cycle (Kofman and Belmaker, 1993). This finding constituted evidence that this model depends on inositol depletion. The fact that the adult $I M P A 1^{-/-}$mice did not show reduced inositol levels in various brain regions does not rule out inositol depletion as a mechanism of the observed seizures. Several pools of inositol are suggested to exist in the brain (Bersudsky et al, 1994; Brand et al, 1993; Fisher et al, 2002; Frey et al, 1998; Novak et al, 1999, 2000a, b) and the IMPA1-dependent inositol pool likely makes up only a small, possibly spatially delineated but clearly significant part. Actually, inositol depletion as a result of dietary inositol restriction (Shaldubina et al, 2006b) or hyponatremia (Bersudsky et al, 1994) has been shown not to sensitize pilocarpine-induced seizures. Along the same line, we recently reported that SMIT heterozygote knockout mice showed reduction in brain inositol levels by about $15-20 \%$, but did not show increased pilocarpine sensitivity (Shaldubina et al, 2006a). SMIT in brain seems to be limited to glia cells (Di Daniel et al, 2006), and it may well be that most of the inositol measured in whole brain is glial inositol. The reduction in brain inositol in $I M P A 1^{-1-}$ mice would be more likely to occur in those cells with a highly active PI cycle such that inositol is being depleted because of it being continuously used and the inability of cells to recycle it. Moreover, measurement of inositol- 1-phosphate levels has been shown in lithium-treated animals to be a more sensitive indicator of such blockade than inositol reduction (Allison et al, 1976) and will be investigated in the future.

While acute high-dose lithium does classically reduce brain inositol in vivo (Allison and Steward, 1971), chronic lithium at therapeutically relevant concentrations has only a small (10-15\%) and inconsistent effect (Lubrich et al, 1997). Thus lack of marked inositol lowering in the IMPA1 knockout mice might also, surprisingly, make these mice a more rather than less realistic model of chronic lithium treatment. While IMPA2 upregulation as compensation was not demonstrated in this study, it is possible that upregulation of SMIT could be a factor to ameliorate the effect of IMPA1 knockout on total brain inositol without eliminating the shortage of inositol in some specific behavior-related pools (van Calker and Belmaker, 2000).

In the IMPA $1^{-}$mice, brain IMPase activity was found to be significantly reduced (up to $65 \%$ in hippocampus), however, considerable residual IMPase activity remained. The existence of residual IMPase activity could make the mouse model at hand, serendipitously, a better model of a lithium-treated animal, since the $\mathrm{Ki}$ of lithium for IMPase indicates that at therapeutic concentrations, the enzyme activity in brain during in vivo treatment is inhibited to about $50 \%$. Today, only IMPA1 and IMPA2 genes have been reported to encode proteins with IMPase activity. IMPA2 knockout mice showed normal IMPase activity in brain (Cryns et al, 2007) confirming previous reports suggesting that IMPA1 is the predominant gene expressed in brain (Agam et al, 2002). While IMPAI knockout mice, described in the present study, appear to have a residual transcript, it is unlikely that a functional protein is formed. In the IMPA1 knockout mice at hand, we deleted the coding region of exon 2 apart from the first seven nucleotides as well as exon 3 and, as such, the coding sequence of 60 out of the 277 amino acids that make up the IMPA1 protein. No alternative splice forms or alternative start sites have been described for the mouse IMPA1 gene (Shamir et al, 2001). In case exon 2 and 3 are skipped, the following first potential start codon is located in exon 5 and would result in a truncated protein starting at amino acid 117. Such a truncated protein would, most likely, not have any IMPase activity since the deleted fragment (amino acids 1-116) contains several amino acids essential for the enzymatic activity of IMPA1 (Bone et al, 1994; Ganzhorn et al, 1996). From our expression analysis, we conclude that the absence of IMPA1 was not compensated by induction of the expression of the IMPA2 protein. Alternatively, there might be an as yet unknown protein yielding lithium inhibitable IMPase activity expressed in the brain. Some evidence for such a third IMPase exists (NCBI Genebank AY032885). The appearance of pilocarpine-induced seizures in IMPA $1^{-/-}$mice (present study), but absence in IMPA2 $2^{-/-}$ mice (Cryns et al, 2007) suggests that the IMPA1-meditated IMPase activity is a limiting factor in the development of pilocarpine-induced seizures. Moreover, a recent paper by Ohnishi et al (2007) has defined for the first time the biochemical properties of IMPA2. IMPA2 is not lithium inhibitable until concentrations far above those obtainable in vivo, which strongly suggests that it could not be involved in the mechanism of lithium action nor could its 
upregulation compensate for knockout of IMPA1. The fact that IMPA1 $1^{-/}$mice survived for 21 days on inositoldeficient diet supports the concept that as yet unidentified pathway for synthesis of inositol exists.

The IMPA $1^{-1-}$ mice displayed reduced immobility in the forced-swim test, which might be suggestive of an antidepressant-like phenotype. Chronic lithium administration in rodents is reported to lead to reduced immobility in the forced-swim test (O'Brien et al, 2004), which suggests that the IMPA1 $1^{-/}$mice might have a lithium-like phenotype in the forced-swim test, and thus, that this lithium effect is mediated by IMPA1 inhibition. We tried to evaluate this by studying the effect of chronic lithium administration on the observed reduced immobility in the IMPA $1^{-/-}$mice. Chronic treatment of mice with $0.4 \%$ lithium carbonate, a dose that has been reported to result in reduced immobility in the forced-swim test, was shown to be toxic and result in lethality in about $50 \%$ on the subjects (see Materials and methods; Cryns et al, 2007). The chronic treatment with $0.2 \%$ lithium carbonate did not result in a reduced immobility in the forced-swim test in wild-type IMPA1 mice. Therefore, it is still not known whether the observed reduced immobility in the $I M P A 1^{-/-}$mice is rendered insensitive to lithium, and thus, represents an IMPA1-mediated lithium-dependant behavior. The IMPA1 $1^{-1-}$ mice are hyperactive in the open-field test and show increased rearing as well. Therefore, the observed reduction in immobility might reflect increased locomotor behavior rather than an antidepressant-like phenotype. On the other hand, the hyperactivity in the open-field test appears to be a consequence of a lack of habituation to the novel environment seen after $25 \mathrm{~min}$ rather than an overall increased locomotor activity. Further testing of these animals in models of depression that are sensitive to lithium but not dependent on activity is required.

The observed hyperactivity in the IMPA $1^{-/-}$mice is likely a neurodevelopmental effect of inositol depletion in utero, despite the absence of obvious neurohistological abnormalities. Recently, the effect of chronic lithium treatment during the developmental period was studied (Youngs et al, 2006). A prominent feature in adulthood of animals receiving lithium treatment during development is hyperactivity, similar to our finding in these IMPase-deleted mice. Furthermore, supplementing adult $\mathrm{IMPA} 1^{-/-}$mice with inositol did not revert the observed hyperactivity, suggesting that the hyperactivity is not a consequence of depleted inositol in adulthood. Separation of these developmental and probably irreversible effects of early IMPase inhibition from pharmacological effects of IMPase inhibition in adult animals could require creation of a conditional or inducible knockout of IMPase.

In conclusion, the IMPA $1^{-/-}$mouse represent a novel model to study inositol homeostasis since our results indicate that reduction in IMPA1-mediated IMPase activity in the brain results in an increased motor activity in both the open-field test and the forced-swim test as well as a strongly increased sensitivity to pilocarpine-induced seizures. The latter supports the idea that IMPA1 represents a physiologically relevant target for lithium. Whether IMPA1 is involved in other lithium-sensitive physiological effects remains to be investigated further.

\section{ACKNOWLEDGEMENTS}

We thank Hansfried Van Craenendonck, for his assistance in the behavioral analysis; Peter Delille, for his assistance in the embryo analysis.

\section{DISCLOSURE/CONFLICT OF INTEREST}

There were no conflicts of interest for the authors Kim Cryns, Alon Shamir, Nathalie Van Acker, Itzhak Levi, Guy Daneels, Ilse Goris, J Adriaan Bouwknecht, Luc Andries, Stefan Kass, Galila Agam, RH Belmaker, Yuly Bersudsky, Thomas Steckler, and Dieder Moechars.

\section{REFERENCES}

Agam G, Shamir A, Shaltiel G, Greenberg ML (2002). Myo-inositol1-phosphate (MIP) synthase: a possible new target for antibipolar drugs. Bipolar Disord 4: 15-20.

Allison JH, Blisner ME, Holland WH, Hipps PP, Sherman WR (1976). Increased brain myo-inositol 1-phosphate in lithiumtreated rats. Biochem Biophys Res Commun 71: 664-670.

Allison JH, Stewart MA (1971). Reduced brain inositol in lithiumtreated rats. Nat New Biol 233: 267-268.

Atack JR, Broughton HB, Pollack SJ (1995). Inositol monophosphatase-a putative target for $\mathrm{Li}+$ in the treatment of bipolar disorder. Trends Neurosci 18: 343-349.

Batty IH, Downes CP (1994). The inhibition of phosphoinositide synthesis and muscarinic-receptor-mediated phospholipase $\mathrm{C}$ activity by $\mathrm{Li}+$ as secondary, selective, consequences of inositol depletion in 1321N1 cells. Biochem J 297(Pt 3): 529-537.

Berrettini WH, Ferraro TN, Goldin LR, Weeks DE, Detera-Wadleigh S, Nurnberger Jr JI et al (1994). Chromosome 18 DNA markers and manic-depressive illness: evidence for a susceptibility gene. Proc Natl Acad Sci USA 91: 5918-5921.

Berridge MJ, Downes CP, Hanley MR (1982). Lithium amplifies agonist-dependent phosphatidylinositol responses in brain and salivary glands. Biochem J 206: 587-595.

Berridge MJ, Downes CP, Hanley MR (1989). Neural and developmental actions of lithium: a unifying hypothesis. Cell 59: 411-419.

Berridge MJ, Irvine RF (1989). Inositol phosphates and cell signalling. Nature 341: 197-205.

Bersudsky Y, Kaplan Z, Shapiro Y, Agam G, Kofman O, Belmaker RH (1994). Behavioral evidence for the existence of two pools of cellular inositol. Eur Neuropsychopharmacol 4: 463-467.

Bone R, Frank L, Springer JP, Pollack SJ, Osborne SA, Atack JR et al (1994). Structural analysis of inositol monophosphatase complexes with substrates. Biochemistry 33: 9460-9467.

Brand A, Richter-Landsberg C, Leibfritz D (1993). Multinuclear NMR studies on the energy metabolism of glial and neuronal cells. Dev Neurosci 15: 289-298.

Chau JF, Lee MK, Law JW, Chung SK, Chung SS (2005). Sodium/ myo-inositol cotransporter-1 is essential for the development and function of the peripheral nerves. FASEB J 19: 1887-1889.

Cryns K, Shamir A, Shapiro J, Daneels G, Goris I, Van Craenendonck $\mathrm{H}$ et al (2007). Lack of lithium-like behavioral and molecular effects in IMPA2 knockout mice. Neuropsychopharmacology 32: 881-891.

Di Daniel E, Cheng L, Maycox PR, Mudge AW (2006). The common inositol-reversible effect of mood stabilizers on neurons does not involve GSK3 inhibition, myo-inositol1-phosphate synthase or the sodium-dependent myo-inositol transporters. Mol Cell Neurosci 32: 27-36.

Einat H, Manji HK, Belmaker RH (2003). New approaches to modeling bipolar disorder. Psychopharmacol Bull 37: 47-63. 
Fisher SK, Novak JE, Agranoff BW (2002). Inositol and higher inositol phosphates in neural tissues: homeostasis, metabolism and functional significance. J Neurochem 82: 736-754.

Frey R, Metzler D, Fischer P, Heiden A, Scharfetter J, Moser E et al (1998). Myo-inositol in depressive and healthy subjects determined by frontal $1 \mathrm{H}$-magnetic resonance spectroscopy at 1.5 tesla. J Psychiatr Res 32: 411-420.

Ganzhorn AJ, Lepage P, Pelton PD, Strasser F, Vincendon P, Rondeau JM (1996). The contribution of lysine-36 to catalysis by human myo-inositol monophosphatase. Biochemistry 35: 10957-10966.

Goodwin FK, Jamison KR (1990). Manic-Depressive Illness. Oxford University Press: New York.

Hallcher LM, Sherman WR (1980). The effects of lithium ion and other agents on the activity of myo- inositol-1-phosphatase from bovine brain. J Biol Chem 255: 10896-10901.

Harwood AJ (2005). Lithium and bipolar mood disorder: the inositol-depletion hypothesis revisited. Mol Psychiatry 10: 117-126.

Honchar MP, Olney JW, Sherman WR (1983). Systemic cholinergic agents induce seizures and brain damage in lithium-treated rats. Science 220: 323-325.

Kofman O, Belmaker RH (1993). Ziskind-Somerfeld Research Award 1993. Biochemical, behavioral, and clinical studies of the role of inositol in lithium treatment and depression. Biol Psychiatry 34: 839-852.

Kofman O, Sherman WR, Katz V, Belmaker RH (1993). Restoration of brain myo-inositol levels in rats increases latency to lithium-pilocarpine seizures. Psychopharmacology (Berl) 110: 229-234.

Lubrich B, Patishi Y, Kofman O, Agam G, Berger M, Belmaker RH et al (1997). Lithium-induced inositol depletion in rat brain after chronic treatment is restricted to the hypothalamus. Mol Psychiatry 2: 407-412.

Novak JE, Agranoff BW, Fisher SK (2000a). Increased expression of Galpha(q/11) and of phospholipase-Cbeta1/4 in differentiated human NT2-N neurons: enhancement of phosphoinositide hydrolysis. J Neurochem 74: 2322-2330.

Novak JE, Agranoff BW, Fisher SK (2000b). Regulation of Myo-inositol homeostasis in differentiated human NT2-N neurons. Neurochem Res 25: 561-566.

Novak JE, Turner RS, Agranoff BW, Fisher SK (1999). Differentiated human NT2-N neurons possess a high intracellular content of myo-inositol. J Neurochem 72: 1431-1440.

O'Brien WT, Harper AD, Jove E, Woodgett JR, Maretto S, Piccolo S et al (2004). Glycogen synthase kinase-3beta haploinsufficiency mimics the behavioral and molecular effects of lithium. J Neurosci 24: 6791-6798.
Ohnishi T, Ohba H, Seo KC, Im J, Sato Y, Iwayama Y et al (2007). Spatial expression patterns and biochemical properties distinguish a second myo-inositol monophosphatase IMPA2 from IMPA1. J Biol Chem 282: 637-646.

Patel S, Meldrum BS, Fine A (1988). Susceptibility to pilocarpineinduced seizures in rats increases with age. Behav Brain Res 31: 165-167.

Rojas K, Liang L, Johnson EI, Berrettini WH, Overhauser J (2000). Identification of candidate genes for psychiatric disorders on 18p11. Mol Psychiatry 5: 389-395.

Shaldubina A, Johanson RA, O'Brien WT, Buccafusca R, Agam G, Belmaker RH et al (2006a). SMIT1 haploinsufficiency causes brain inositol deficiency without affecting lithium-sensitive behavior. Mol Genet Metab 88: 384-388.

Shaldubina A, Stahl Z, Furszpan M, Regenold WT, Shapiro J, Belmaker RH et al (2006b). Inositol deficiency diet and lithium effects. Bipolar Disord 8: 152-159.

Shamir A, Sjoholt G, Ebstein RP, Agam G, Steen V (2001). Characterization of genes encoding mouse myo-inositol monophosphatase (Impa1 and Impa2). Gene 271: 285-289.

Shapiro J, Belmaker RH, Biegon A, Seker A, Agam G (2000). Scylloinositol in post-mortem brain of bipolar, unipolar and schizophrenic patients. J Neural Transm 107: 603-607.

Sjoholt G, Gulbrandsen AK, Lovlie R, Berle J, Molven A, Steen VM (2000). A human myo-inositol monophosphatase gene (IMPA2) localized in a putative susceptibility region for bipolar disorder on chromosome 18p11.2: genomic structure and polymorphism screening in manic-depressive patients. Mol Psychiatry 5: $172-180$.

van Calker D, Belmaker RH (2000). The high affinity inositol transport system-implications for the pathophysiology and treatment of bipolar disorder: an editorial. Bipolar Disord 2: 102-107.

Yoshikawa T, Padigaru M, Karkera JD, Sharma M, Berrettini WH, Esterling LE et al (2000). Genomic structure and novel variants of myo-inositol monophosphatase 2 (IMPA2). Mol Psychiatry 5: 165-171.

Yoshikawa T, Turner G, Esterling LE, Sanders AR, DeteraWadleigh SD (1997). A novel human myo-inositol monophosphatase gene, IMP.18p, maps to a susceptibility region for bipolar disorder. Mol Psychiatry 2: 393-397.

Youngs RM, Chu MS, Meloni EG, Naydenov A, Carlezon Jr WA, Konradi C (2006). Lithium administration to preadolescent rats causes long-lasting increases in anxiety-like behavior and has molecular consequences. J Neurosci 26: 6031-6039.

Zambrowicz BP, Friedrich GA (1998). Comprehensive mammalian genetics: history and future prospects of gene trapping in the mouse. Int J Dev Biol 42: 1025-1036. 